\title{
Construction and Evaluation of Management Service Index System of Inner Mongolia Hospital for the Nationalities
}

\author{
Huilin An \\ School of Humanities, Social Sciences and Foreign Language \\ Baotou Medical College \\ Baotou, Inner Mongolia, 014060, China
}

\begin{abstract}
Hospitals for the nationalities mainly signifying Mongolian hospitals in this work are compared with comprehensive hospitals, traditional Chinese medicine hospitals, integrated traditional Chinese and western medicine hospitals, and specialized hospitals in terms of cross-section data. It aims to evaluate the management service level of Mongolian hospitals and look for its strengths and weaknesses, so as to promote the high-quality development of Mongolian hospitals. Based on the literature research method, this work used the entropy method to weight the constructed index system and carry out a comprehensive evaluation to obtain comprehensive evaluation values for various types of hospitals. It constructed 22 indicators in four dimensions. It was found that Mongolian hospitals still have certain gaps compared with other types of hospitals in terms of infrastructure utilization efficiency, hospitalization cycle and drug prices. Finally, this work proposed some possible solutions to these problems.
\end{abstract}

Keywords-Hospital for the Nationalities; Management service; Index system; Evaluation of Management Service Index System

\section{INTRODUCTION}

The report of the 19th National Congress of the Communist Party of China pointed out that it is necessary to implement the Healthy China Strategy and the comprehensive establishment of a high-quality and efficient medical and health service system. It requires attaching equal importance to traditional Chinese and western medicine as well as carry forward and develop the cause of traditional Chinese medicine. Ethnic medicine is an important part of traditional Chinese medicine and Mongolian medicine is one of the important branches of ethnic medicine. The high quality and high efficiency of Mongolian medical and health management service system is an important way to implement the Healthy China Strategy. Improving Mongolian medical service capabilities and effects can become an important carrier of Mongolian medicine culture. For a long time, the local ethnic medicine administrative units have only taken more and more measures to manage Mongolian medical institutions. How to improve the management service efficiency of Mongolian medical institutions and better provide efficient medical services to the people is an important part of deepening the reform of the health system. This work compared Hospitals for the nationalities (mainly refer to Mongolian hospitals) (hereinafter referred to as Mongolian hospitals) with comprehensive hospitals, traditional Chinese medicine hospitals, integrated traditional Chinese and western medicine hospitals, and specialized hospitals in terms of infrastructure construction, medical service capabilities, financial costs and medical service effect. This work tried to find out the direction and focus of future reform by comparing the strengths and weaknesses of Mongolian hospitals with other types of hospitals.

\section{Evaluation OF THE INDEX SySTEM CONSTRUCTION} FOR THE MANAGEMENT SERVICE IN NATIONALITY Hospitals

\section{A. Construction of the index system}

In order to more objectively evaluate the level of Mongolian medical management service, sample data analysis was performed using Inner Mongolia Hospital as an example according to the availability of data. This work compared Hospitals for the nationalities (mainly refer to Mongolian hospitals) (hereinafter referred to as Mongolian hospitals) with comprehensive hospitals, traditional Chinese medicine hospitals, integrated traditional Chinese and western medicine hospitals, and specialized hospitals in terms of infrastructure construction, medical service capabilities, financial costs and medical service effect. Through the comparison of horizontal data in 2016, the strengths and weaknesses of nationality hospitals can be explored.

Mongolian medicine is an important part of the national medicine system, so its development reflects the level of national medicine service in China to a certain extent. Taking into account the availability of evaluation indicators and data for management services of Mongolian medicine hospitals, 22 indicators are constructed in four dimensions of infrastructure construction, service capacity, health costs and service effects. The indicators include the number of hospitals (unit), the proportion of Class A tertiary hospitals (percentage), the proportion of Class A secondary hospitals (percentage), average number of beds (unit / per), average number of health personnel (persons / per), building area (10,000 square meters), number of consultations (persons), number of patients discharged per bed, number of inpatient operations $(10,000$ person - times), admissions (10,000 person - times), average days of hospitalization, per capita medical expenses $(10,000$ yuan / person), total assets (100 million yuan), current assets (100 million yuan), medical income (100 million yuan), financial subsidy income (100 million yuan), average daily 
burden of doctors for medical treatment (hospitalization plus outpatient), the number of observation cases (10,000 cases) in the observation room, the number of health check-ups $(10,000$ person times), the emergency mortality rate, the hospital mortality rate, and the observation room mortality rate.

\section{B. Sample selection}

The Inner Mongolia Autonomous Region is the main position for Mongolian medicine development services. Based on the statistical dimensions of the 2016 Inner Mongolia Autonomous Region Health Statistics Yearbook, the service situation of nationality hospitals and other types of hospitals can be analyzed. Among them, independent nationality hospitals mainly focus on Mongolian medicine, so the samples should be classified according to the classification criteria of health yearbook.

\section{Using the entropy method to sort the indicators}

The entropy method should be used to weight 22 indexes of four dimensions and to make a comprehensive evaluation. First, a fuzzy relationship matrix should be established based on the original data of the indicator; second, the forward and reverse indicators should be performed dimensionless processing respectively; then, the entropy of the indicator and the coefficient of difference between the indicators should be calculated and the weight should be determined (see Table I); Finally, the comprehensive evaluation value of each type of hospital should be calculated (see Table II).

TABLE I. INDICATOR ENTROPY VALUE, COEFFICIENT OF DIFFERENCE AND WEIGHT

\begin{tabular}{|c|c|c|c|}
\hline Indicator name & Entropy & $\begin{array}{l}\text { Coefficient of } \\
\text { difference }\end{array}$ & Weights \\
\hline Number of hospitals & 0.9806 & 0.0194 & 0.0422 \\
\hline $\begin{array}{c}\text { Proportion of Class A tertiary } \\
\text { hospitals (\%) }\end{array}$ & 0.9834 & 0.0166 & 0.0362 \\
\hline $\begin{array}{c}\text { Proportion of Class A secondary } \\
\text { hospitals (\%) }\end{array}$ & 0.9731 & 0.0269 & 0.0585 \\
\hline Average number of beds & 0.9805 & 0.0195 & 0.0425 \\
\hline $\begin{array}{l}\text { Average number of health } \\
\text { personnel (persons / per) }\end{array}$ & 0.9839 & 0.0161 & 0.0351 \\
\hline $\begin{array}{l}\text { Average construction area } \\
(10,000 \text { square meters })\end{array}$ & 0.9770 & 0.0230 & 0.0501 \\
\hline $\begin{array}{l}\text { Number of consultations } \\
\text { (persons) }\end{array}$ & 0.9766 & 0.0234 & 0.0509 \\
\hline Discharges per bed & 0.9804 & 0.0196 & 0.0427 \\
\hline $\begin{array}{c}\text { Number of inpatient operations } \\
(10,000 \text { person-times })\end{array}$ & 0.9837 & 0.0163 & 0.0355 \\
\hline $\begin{array}{l}\text { Number of admissions }(10,000 \\
\text { person - times) }\end{array}$ & 0.9754 & 0.0246 & 0.0535 \\
\hline Average hospitalization day & 0.9845 & 0.0155 & 0.0338 \\
\hline $\begin{array}{l}\text { Medical expenses per capita } \\
\text { (10,000 yuan / person) }\end{array}$ & 0.9834 & 0.0166 & 0.0362 \\
\hline Total assets (100 million yuan) & 0.9762 & 0.0238 & 0.0519 \\
\hline Current assets (100 million yuan) & 0.9762 & 0.0238 & 0.0518 \\
\hline $\begin{array}{l}\text { Pharmaceutical revenue (100 } \\
\text { million yuan) }\end{array}$ & 0.9799 & 0.0201 & 0.0437 \\
\hline $\begin{array}{l}\text { Financial subsidy income (100 } \\
\text { million yuan) }\end{array}$ & 0.9753 & 0.0247 & 0.0539 \\
\hline $\begin{array}{c}\text { Physician average daily } \\
\text { consultations (inpatient plus } \\
\text { outpatient) }\end{array}$ & 0.9838 & 0.0162 & 0.0353 \\
\hline $\begin{array}{l}\text { Number of observation cases in } \\
\text { observation room (10,000 cases) }\end{array}$ & 0.9830 & 0.0170 & 0.0370 \\
\hline
\end{tabular}

\begin{tabular}{|c|c|c|c|}
\hline \multicolumn{4}{|c|}{ Cont. to TABLE I. } \\
\hline $\begin{array}{c}\text { Number of health checkups } \\
(10,000 \text { person - times })\end{array}$ & 0.9837 & 0.0163 & 0.0355 \\
\hline Emergency mortality & 0.9629 & 0.0371 & 0.0807 \\
\hline Hospital mortality & 0.9763 & 0.0237 & 0.0515 \\
\hline $\begin{array}{c}\text { Mortality rate in observation } \\
\text { room }\end{array}$ & 0.9809 & 0.0191 & 0.0416 \\
\hline
\end{tabular}

TABLE II. COMPREHENSIVE EVALUATION VALUES OF VARIOUS TYPES OF HOSPITALS

\begin{tabular}{|c|c|c|}
\hline Hospital type & $\begin{array}{c}\text { Comprehensive evaluation } \\
\text { value }\end{array}$ & Ranking \\
\hline Comprehensive hospital & 0.5883 & 1 \\
\hline $\begin{array}{c}\text { Traditional Chinese medicine } \\
\text { hospital }\end{array}$ & 0.3630 & 4 \\
\hline $\begin{array}{c}\text { Asia and Europe combined } \\
\text { hospital }\end{array}$ & 0.3033 & 5 \\
\hline National hospital & 0.3938 & 2 \\
\hline Specialist hospital & 0.4910 & \\
\hline
\end{tabular}

\section{Scoring and ranking}

The weight is calculated using the entropy method, and the comprehensive evaluation value is calculated. The final comprehensive evaluation value ranking of each type of hospital is obtained according to the index system constructed in the work. The comprehensive evaluation value of the comprehensive type hospital is 0.5883, ranking first; the comprehensive evaluation value of the specialty hospital is 0.4910 , ranking second; comprehensive evaluation value of national hospitals is 0.3938, ranking third; comprehensive evaluation value of traditional Chinese medicine hospitals is 0.3630 , ranking fourth; comprehensive evaluation value of integrated traditional Chinese and western medicine hospitals is 0.3033, which is in the final position.

\section{ANALYSIS ON THE EVALUATION RESULT OF THE \\ MANAGEMENT SERVICE INDEX SYSTEM OF NATIONALITY HOSPITALS}

From the perspective of infrastructure construction, by comparing the indicators of 5 types of hospitals, the number of nationality hospitals ranks fourth, but the proportion of Class A tertiary hospitals and Class A secondary hospitals ranks first. It reflects the fact that Mongolian medicine has been continuously strengthening infrastructure construction, improving medical service conditions, strengthening medical service technology and improving the quality of comprehensive medical service during its long-term service to the people of the autonomous region. To some extent, it reflects that the autonomous region attaches great importance to the development of Mongolian medicine. Under the strong support of the local government and management agencies, it gradually forms a trapezoidal structure that takes regional Mongolian medicine hospitals as the lead, municipal Mongolian medicine hospitals as the nucleus, and county Mongolian medicine institutions as the basis, gradually forming a huge system of Mongolian medicine service institutions with other types of hospitals, Mongolian medicine and township hospitals and community health service centers as a necessary supplement [1]. 
The average number of beds and the average number of health personnel in nationality hospitals rank second, and the bed utilization rate is 62.3 , which is still slightly different from the overall bed utilization rate of 65.5 in Mongolian and Chinese Hospitals. Therefore, in the future, the efficiency of infrastructure utilization should be improved. Although the number of health personnel ranks second, more than $50 \%$ of the practicing physicians are over 45 years old, 5.01\% are highly educated practitioners (postgraduates), and more than 73\% are junior technicians in Mongolian Traditional Chinese Medicine Hospital. From the perspective of the building area, it can be seen that the average building area of the five types of hospitals is 15997, 6750, 2856, 9609, and 6778.

From the perspective of service capacity, the number of consultations in nationality hospitals is 3.727 million, and the average number of consultations in institutions is 61,100, which is at an intermediate level. The number of discharged patients per bed is 20.7, ranking third. The number of inpatient operations (10,000 person-times) and hospital admissions rank fourth. The average number of hospitalization days ranks second, which shows that the hospitalization cycle is relatively long. This has a certain relationship with the traditional natural green medicine and nationality medical practices. In contrast, comprehensive hospitals and hospitals of traditional Chinese and Western medicine have quick effects and short cycle time by using modern western medical technology [2]. However, as an important component of Chinese medicine, nationality medicine is an indispensable intangible cultural heritage that should be protected. Nationality hospitals should take their advantages to take differentiated services, so as to build a modern medical consortium for ethnic medicine and deepen medical reform.

From the perspective of financial costs, the medical costs of nationality hospitals are relatively high, second only to specialized hospitals. The total assets of nationality hospitals are 4.306 billion yuan, and the average total assets are 71 million yuan, ranking second. The first place is comprehensive hospitals with average assets of 111 million yuan. Its average current assets are also in the second position. Although its average medical income ranks first, the average financial income received is second. The relatively high medical expenses of nationality hospitals are closely related to medical income. Taking Mongolian medicine as an example, there are more than 2,200 varieties of Mongolian medicine, and there are more than 1,300 more commonly used medicines [3]. However, in the National Medical Insurance Catalog, there are only 27 varieties of Mongolian medicine. In the list of medical insurance of the Inner Mongolia Region, there are 122 varieties included in the supplementary medical insurance catalogue. The proportion of Mongolian medicines covered by medical insurance is $11 \%$ of common medicines, less than $7 \%$ of Mongolian medicines. Therefore, including more common Mongolian medicines in medical insurance will effectively reduce the burden on local residents to seek medical treatment.

From the perspective of service effect, the average daily burden of doctors (inpatient plus outpatient) in nationality hospitals is 6.1. Compared with other types of hospitals, the burden is not too heavy. The number of observation cases $(10,000$ cases) in the observation room of nationality hospitals is 2.13, but the average number of observation cases in the observation room is 0.035 million, which is only higher than that of specialized hospitals. The number of health checkups is 135,000 , and the average number of health checkups is 0.22 , ranking first. Due to the increasing influence of Mongolian medicine and increasingly close cultural exchange, the Mongolian medical service population is not limited to local residents, but expands to people in neighboring provinces. Even people in Mongolia, Russia and Japan and other countries come to Mongolian medical hospitals for examinations and medical treatments [4]. The emergency hospital fatality rate of nationality hospitals is at an average level. The mortality rate in the observation room of the nationality hospital is relatively low.

\section{SUMMARY}

Through the above analysis, it can be seen that the development of Mongolian hospitals in the region has given certain preferential policies. However, due to the characteristics of Mongolian medical hospitals, some shortcomings have also been exposed during the comparison with other types of hospitals. Therefore, they should take several methods to develop medical cause and make up for their own shortcomings. Mongolian medical institutions should be encouraged to actively develop Mongolian medicine and other types of medical consortia with well-known hospitals at home and abroad to promote the sinking of high-quality medical resources and drive the development of Mongolian medicine in the region [5]. Relevant departments should increase grassroots Mongolian medical support and optimize the allocation of grass-roots Mongolian medicine resources. In this way, the grass-roots Mongolian medical institutions can be promoted out of nothing, and to refinement. The grass-roots Mongolian medicine service capacity building should be strengthened to promote the establishment of hierarchical diagnosis and treatment, diagnosis and treatment model of urgent and slow division and two-way referrals, so that it can realize the rational use of resources and deepen the reform of the Mongolian medicine and health system. Mongolian medical institutions should attach equal importance to the integration of internal and external sources and increase the linkage among the government, enterprises, universities, research institutes and hospitals, so as to promote the deep integration of the Mongolian medicine industry, education, research and application. Related departments and personnel should also attach great importance to the cultural dissemination of Mongolian medicine. Through organization linkage and unified planning, the dissemination form can be enriched. With the help of the authoritative power of traditional media, the audience group and scope of Mongolian medicine can be expanded.

\section{REFERENCES}

[1] Fan Wenhui, Li Yun, An Huilin, et al. Research on the Supervision Problem of Mongolian Medicine in Inner Mongolia[J]. Legality Vision, 2017, (32): 57-58.(In Chinese)

[2] Feng Zhe, Huang Yourong, et al. The Integration of Traditional Chinese Medicine and Western Medicine is the Unity of Systematic Management and Personalized Treatment - Seeing the Integration of Traditional Chinese Medicine and Western Medicine from the Perspective of the 
[4] Sa Rula. Exploration of Youth Volunteer Service in National Medical Hospital - Taking Inner Mongolia International Mongolia Medical Hospital as an Example[J]. Chinese Journal of National Medical Medicine, 2017, (4): 71 - 72. (In Chinese)

[3] Ce Li Mu Ge, Song Lin, Liu Meng Jiao, et al. Mongolian Medicine Characteristics and Development Ideas[J]. Chinese Journal of Library and Information Science for Traditional Chinese Medicine, 2016,40 (6): 4 - 9. (In Chinese)

[5] Tao Shuxia, Li Xiaobo. Status and Development Thinking of Mongolian Medicine in Liaoning Province[J]. Chinese Journal of National Medicine, 2017, (9): 64 - 66. (In Chinese) 